American Journal of Applied Sciences 7 (5): 717-723, 2010

ISSN 1546-9239

(C) 2010Science Publications

\title{
Land Surface Temperature Retrieval by Using ATCOR3_T and Normalized Difference Vegetation Index Methods in Penang Island
}

\author{
K.C. Tan, H.S. Lim, M.Z. MatJafri and K. Abdullah \\ School of Physics, University Sains Malaysia, 11800 Penang, Malaysia
}

\begin{abstract}
Problem statement: Many studies have been devoted to establish the methodology for retrieval of LST from single channel algorithm by utilizing Landsat satellite images. However, this method required many atmospheric parameters to retrieve LST. Thus, it is very difficult to acquire the complete information for atmospheric parameters. Approach: While for ATCOR3_T, this method can be used to retrieve LST without any historical atmospheric parameters like transmittance and meanatmospheric temperature. In this study, the retrieval of LST value from ATCOR3_T method was compared with the NDVI method, in order to calculate the average percentage of error. Results: The obtained result showed that the LST value retrieved from ATCOR3 T can be used to generate the LST map in equatorial region, such as Penang Island. The average percentage of error for 40 points of LST gives the percentage of $5.13 \%$. Conclusion/Recommendations: Both of these methods can be used to estimate LST value in the study area. In addition, the retrieval of LST value from multi-temporal satellite images is useful to study urban heat island effects in Penang Island for future study.
\end{abstract}

Key words: ATCOR3_T, LST, Landsat 7 ETM+

\section{INTRODUCTION}

Land Surface Temperature (LST) controlled by the surface energy balance, atmospheric state, thermal properties of the surface and subsurface media, is an important factor controlling most physical, chemical and biological processes of the Earth (Becker and Li, 1990). However, the radiance converted from digital number does not represent a true surface temperature but a mixed signal or the sum of different fractions of energy. The methods that are popularly used in correction of satellite observations of surface radiance for atmospheric effects fall into two categories, the direct methods which use atmospheric soundings of temperature and moisture from balloon-borne sonde and the indirect approaches which attempt to accomplish atmospheric corrections with satellite observations only (Norman et al., 1995). Direct methods combine in situ measurements of temperature and moisture with atmospheric radioactive transfer models, such as LOWTRAN and MODTRAN, which calculate the atmospheric transmittance and path radiance as a function of wavelength. Indirect methods derive vertical soundings of the atmosphere from satellite observations and use atmospheric radioactive transfer models (Yang and Wang, 2002).
LST is a key parameter in the physics of land surface processes because it is involved in the energy balance as well as in the evapotranspiration and desertification processes. LST is a good indicator of land degradation and climate change and may be used for drought detection and impact assessment based on the estimation of indices of vegetation stress, especially designed to monitor vegetation health, moisture and thermal conditions (Peres and Dacamara, 2004).

The remote sensing of LST became an important topic especially in academic for research purpose since last two decades. This is due to the extensive requirement of LST in management activities of Earth's resources and the environmental studies (Qin and Karnieli, 1990). LST plays main role in the equilibrium, which in thermodynamic state. Therefore, its affects the energy balances of the fluxes, between the Earth's surface, atmosphere and subsurface (Schmugge et al., 2002).

There are few methods to retrieve LST using remote sensing technique, such as mono-window algorithm, split-window algorithm (Jiang and Li, 2008). All of these methods utilized multi-temporal satellite images to retrieve LST. Furthermore, they require the exact atmospheric profiles to successfully determine the historical LST value. Hence, lack of the atmospheric

Corresponding Author: K.C. Tan, School of Physics, University Sains Malaysia, 11800 Penang, Malaysia Tel: +604-6533888 Fax: +604-6579150 
parameters for the particular day of satellite image acquisition may affect the result of LST retrieval. While for in-situ measurement to acquire ground-truth data, it is very time-consuming, constraint laborious and difficulties in data processing. In addition, the availability of the historical data also restricted for certain period. Besides that, in-situ measurement can be done only for point measurement; therefore it is only restricted to study for small study area. Inversely, satellite measurement can provide quantitatively data with high spatial resolution or temporal-resolution (Dousset and Gourmelon, 2003).

The objective of this study was to retrieve the LST values from Landsat 7 ETM+ thermal band (10.4$12.5 \mu \mathrm{m})$ data. In this study, two methodologies for the LST values retrieval are discussed. The first technique employs ATCOR3_T image correction software and the other one uses the NDVI method. ATCOR3 $\mathrm{T}$ is one method to retrieve LST, which was introduced by Richter (1990). ATCOR3_T generates the surface thermal map using elevation data. It considers the slope and aspect images to retrieve accurate LST values over high mountain terrain. ATCOR3_T is useful to retrieve LST in 3D because DEM need to be used to generate LST map (Richter, 1990). It is not require the atmospheric parameters, like transmittance and meanatmospheric temperature, in order to retrieve LST using satellite image. Besides that, this method can remove atmospheric and topographic effects efficiently. It's also generates the three-dimensional atmosphere by considering the transmittance and radiance functions of different height, included atmospheric conditions alteration in horizontally. Consequently, it is able to solve the problem of haze through the statistical algorithm, which helps to manipulate the optical depths in different altitude.

Study area and data acquisition: The study area is the Penang Island, Malaysia, located within latitudes $5^{\circ} 12^{\prime} \mathrm{N}-5^{\circ} 30^{\prime} \mathrm{N}$ and longitudes $100^{\circ} 09^{\prime} \mathrm{E}-100^{\circ} 26^{\prime} \mathrm{E}$. The map of the study area is shown in Fig. 1.

The government-owned Landsat 7 was successfully launched on April 15, 1999 from the Western Test Range of Vandenberg Air Force Base, California, on a Delta-II expendable launch vehicle. The Earth observing instrument on Landsat 7, the Enhanced

Thematic Mapper Plus $(\mathrm{ETM}+)$ replicates the capabilities of the highly successful Thematic Mapper instruments on Landsats 4 and 5. On May 31, 2003, the Scan Line Corrector (SLC), which compensates for the forward motion of Landsat 7, failed.

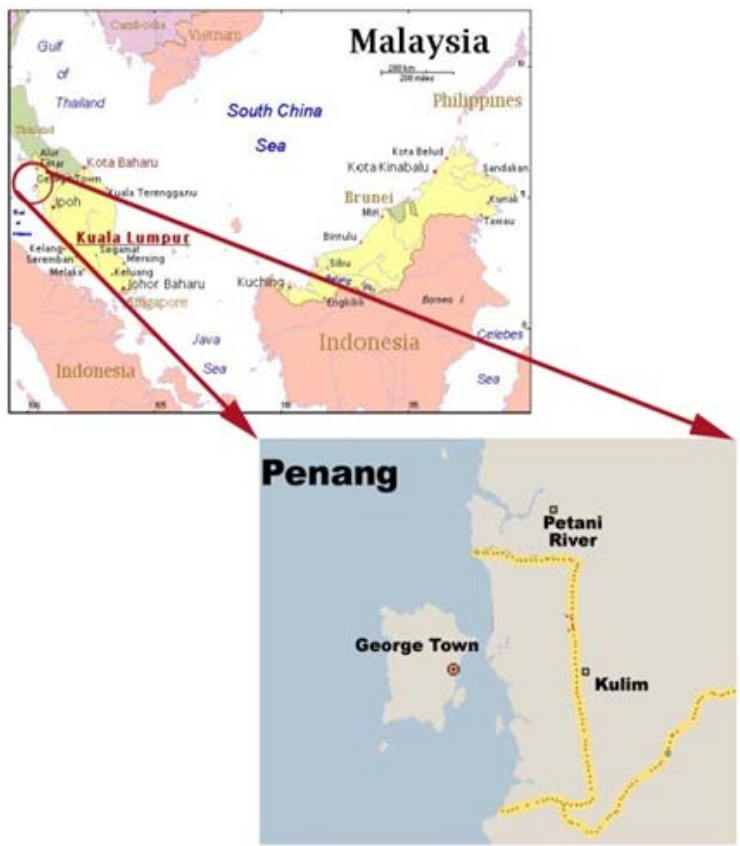

Fig. 1: Study area
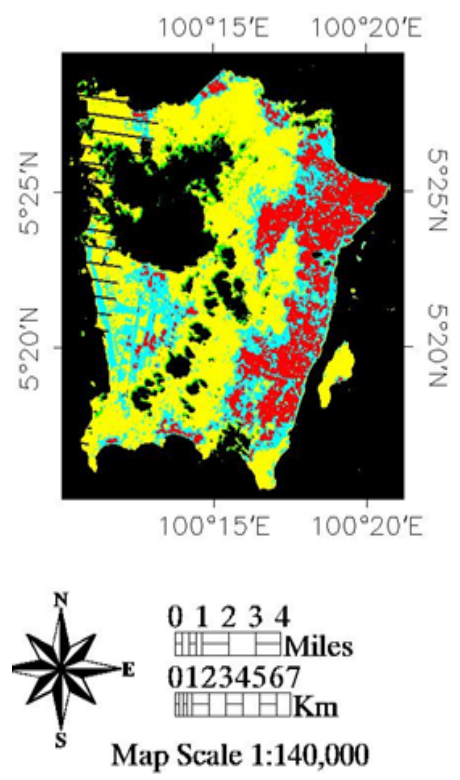

Fig. 2: The raw satellite image, Landsat ETM+ image (path 128/row 56) with band combination RGB $=321$ for the study area

Subsequent efforts to recover the SLC were not successful and the failure appears to be permanent. Without an operating SLC, the Enhanced Thematic 
Mapper Plus (ETM+) line of sight now traces a zig-zag pattern along the satellite ground track (Fig. 2). As a result, imaged area is duplicated, with width that increases toward the scene edge. And the satellite scene downloaded from US.

Geological Survey website was SLC-off image. But, fortunately, the cropped satellite image used in this study area was located centrally of the full satellite scenes that escape of the SLC-off problem (NASA, 2010).

The satellite image was acquired on 23 January 2010 (Fig. 2). The satellite track in path and row is $128 / 56$. Penang Island is located in equatorial region and enjoy a warm equatorial weather whole the year. Therefore, it is impossible to get the $100 \%$ cloud free satellite image over Penang Island. But, the satellite image chosen must have cloud coverage as less as possible.

\section{MATERIALS AND METHODS}

All image-processing tasks carried out using PCI Geomatica version 10.3.1 digital image processing software. LST were retrieved from the radiometrically and geometrically corrected images using ATCOR3_T, in the PCI Geomatica version 10.3.1 image processing software. ATCOR3_T generates the surface thermal map using elevation data. It considers the slope and aspect images to retrieve accurate LST values over high mountain terrain. ATCOR3_T is useful to retrieve LST in 3D because Digital Elevation Model (DEM) needs to be used to generate LST map. Therefore, in this study the reference DEM model, which is Advanced Spaceborne Thermal Emission and Reflection Radiometer (ASTER) have been used to retrieve LST.

Secondly, NDVI was calculated as the ratio between measured reflectance in the red band (R) and Near Infrared (NIR) based on following formula (Xiao and Weng, 2007):

NDVI $=(\rho$ (band 4) $-\rho($ band 3$)) /(\rho \quad$ (band 4) $+\rho($ band 3$))$

where, $\rho$ are the surface reflectance for band 3 and band 4 respectively.

Since Penang Island is located at the equatorial region, the cloud coverage becomes major obstacle in image processing. We need to mask out all the cloud area in the entire satellite image. The cloud mask calls the gross cloud check technique, required brightness temperature value, in order to determine the cloud area. The conversion of brightness temperature from at-sensor radiance is given by (Chander et al., 2009a; 2009b):

$$
\mathrm{T}=\frac{\mathrm{K}_{2}}{\mathrm{LN}\left[\frac{\mathrm{K}_{1}}{\mathrm{~L}_{\lambda}}\right]+1}
$$

Where:

$\mathrm{T}$ = Effective at-sensor brightness temperature (in Kelvin)

$\mathrm{K}_{2}=$ Calibration constant 2 (in Kelvin) [1260.56 for Landsat $5 \mathrm{TM}$ and 1282.71 for Landsat $7 \mathrm{ETM}+]$

$\mathrm{K}_{1}=$ Calibration constant $1\left[\mathrm{~W} /\left(\mathrm{m}^{2} \mathrm{sr} \mu \mathrm{m}\right)\right],[607.76$ for Landsat $5 \mathrm{TM}$ and 666.09 for Landsat 7 $\mathrm{ETM}+]$

$\mathrm{L}_{\lambda}=$ Spectral radiance at the sensor's aperture $[\mathrm{W} /$ $\left.\left(\mathrm{m}^{2} \mathrm{sr} \mu \mathrm{m}\right)\right]$

$\mathrm{LN}=$ Natural logarithm

The other method proposed by (Sobrino et al., 2004), in order to retrieve LST, which is called LST retrieval from emissivity value estimated by NDVI method.

The LST were derived from the corrected ETM+ and TM of TIR band (10.44-12.42 $\mu \mathrm{m})$. The LST were computed as following the equation (Weng et al., 2004):

$$
\mathrm{S}_{\mathrm{t}}=\frac{\mathrm{T}}{1+\left(\lambda \frac{\mathrm{T}}{\mathrm{p}}\right) \text { in } \varepsilon}
$$

Where:

$\mathrm{T}=$ brightness temperature (obtain from Eq. 2)

$\lambda=$ wavelength of emitted radiance (for which the peak response and the average of the limiting wavelengths)

$\rho=\mathrm{h} \times \mathrm{c} / \sigma\left(1.438 \times 10^{-2} \mathrm{~m} \mathrm{~K}\right)$

$\sigma=$ Boltzmann constant $\left(1.38 \times 10^{-23} \mathrm{~J} \mathrm{~K}^{-1}\right)$

$\mathrm{h}=$ Planck's constant $\left(6.626 \times 10^{-34} \mathrm{Js}\right)$

$\mathrm{c}=$ velocity of light $\left(2.998 \times 10^{8} \mathrm{~m} \mathrm{sec}^{-1}\right)$

The corrections for spectral emissivity $(\varepsilon)$ became compulsory due to the natural properties of land cover. The study has been carried out to obtain emissivity from the NDVI method through the method proposed by (Sobrino et al., 2004). 
Am. J. Applied Sci., 7 (5): 717-723, 2010

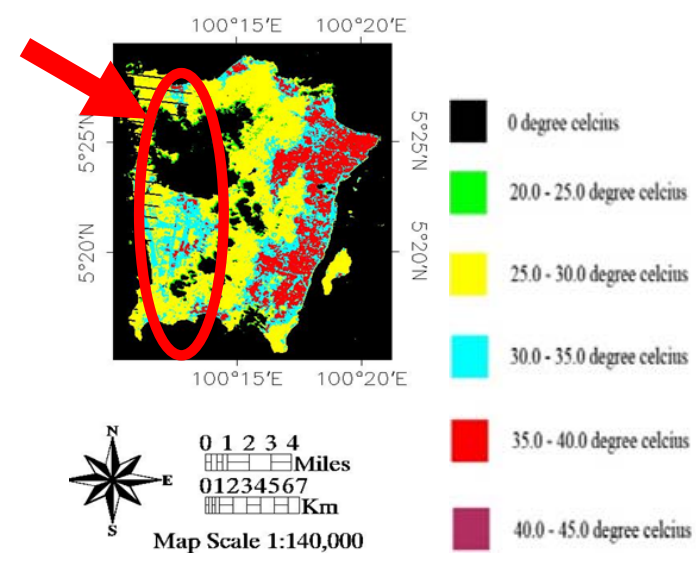

Fig. 3: The generated of LST map using ATCOR3_T method

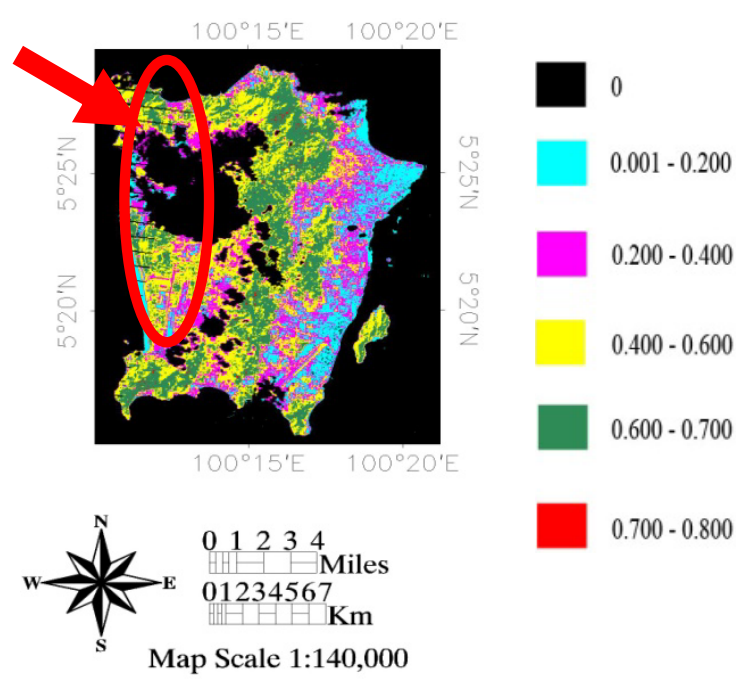

Fig. 4: The NDVI map generated from Landsat 7 ETM+, on 23 January 2010

Data analysis and result: An instrument malfunction occurred onboard Landsat 7 on May 31, 2003. The problem was caused by failure of the Scan Line Corrector (SLC), which compensates for the forward motion of the satellite. Subsequent efforts to recover the SLC have not been successful and the problem is permanent. The Landsat 7 Enhanced Thematic Mapper Plus (ETM+) is still capable of acquiring useful image data with the SLC turned off, particularly within the central portion of any given scene. Landsat $7 \mathrm{ETM}+$ will therefore continue to acquire image data in the "SLC-off" mode (NASA, 2009).

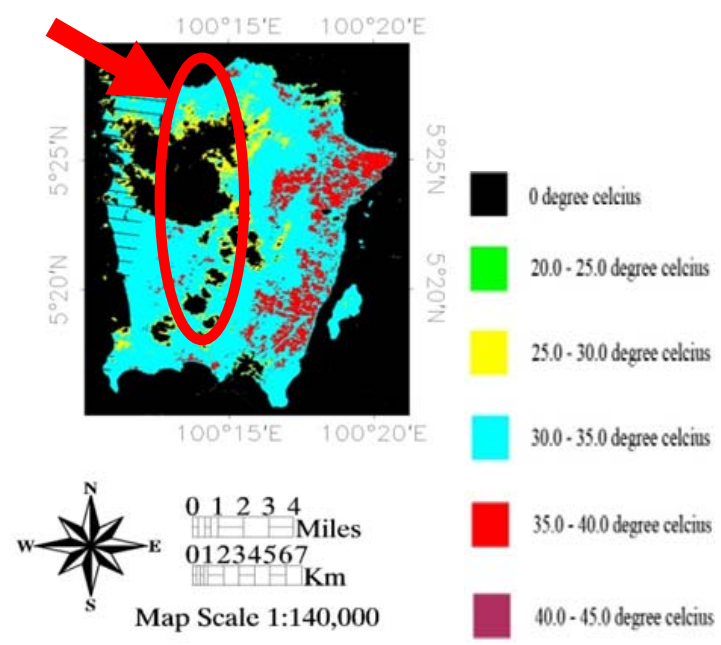

Fig. 5: The generated of LST map using NDVI method

As the Landsat 7 ETM+ faced the problem of malfunction due to the reason of SLC-off, the full scene of the raw satellite for the study area, Penang Island also affected by this problem. But, fortunately the study area of Penang Island, Malaysia was located within the central portion of the full satellite Landsat scene. And the problem of malfunction due to the reason of SLCoff just covered a small part of the study area (northwest of the study area). Hence, the study area with this problem was masked out and become null in this study. In addition, LST values retrieved by using both of the proposed method should not include in the data analysis. Example of the study area affected by SLC-off problem showed in Fig. 3-5 (with the red arrow). However, the study area, which was not affected by this problem, can be used to retrieve LST value.

Many factors affect the retrieval of LST from satellite thermal infrared data but some of them, such as transmittance, air moisture, downwelling and upwelling radiance, are usually difficult to obtain, especially from satellite observations (Yang and Wang, 2002). The generated of LST map through retrieval from ATCOR3_T showed in Fig. 3. From the map, there is a significant difference in terms of the value for LST between the left and right side of the generated map.

Figure 4 showed the NDVI map, computed based on Eq. 1. As compared with LST map (Fig. 3), when the LST value is increasing, the NDVI value is decreasing, or vice-versa. From the NDVI value, we use it to generate LST value, where this method proposed by (Sobrino et al., 2002). In order to evaluate 
the value of LST retrieved from ATCOR3 T and NDVI method, every single point need to calculate the error based on the following equation (Sobrino et al., 2002):

Error $(\%)=\frac{\left|\mathrm{LST}_{\mathrm{ATCOR} 3 \mathrm{~T}}-\mathrm{LST}_{\mathrm{NDVI} \text { method }}\right|}{\mathrm{LST}_{\mathrm{NDVI} \text { method }}}$

The method proposed obtains the emissivity values were obtained from the NDVI as follow:

NDVI<0.2: In this case, the pixel is considered as bare soil and the mean emissivity value used in this study was 0.97 (Sobrino et al., 2004).

NDVI>0.5: Pixels with NDVI values higher than 0.5 are considered as fully vegetated and then a constant value for the emissivity is assumed, typically of 0.99 .

$\mathbf{0 . 2}<\mathrm{NDVI}<0.5$ : In this case, a mixture of the bare soil and vegetation composes the pixel and the emissivity is calculated according to the following equation:

$\varepsilon=\varepsilon_{\mathrm{V}} \mathrm{P}_{\mathrm{V}}+\varepsilon_{\mathrm{S}}\left(1-\mathrm{P}_{\mathrm{V}}\right)+\mathrm{d} \varepsilon$

Where:

$\varepsilon_{\mathrm{v}}=$ The vegetation emissivity and

$\varepsilon_{\mathrm{s}}=$ The soil emissivity,

$\mathrm{P}_{\mathrm{v}}=$ The proportion of vegetation obtained according to other studied (Sobrino et al., 2004):

$\mathrm{P}_{\mathrm{V}}=\left[\frac{\mathrm{NDVI}-\mathrm{NDVI} \text { min }}{\mathrm{NDVI}_{\max }-\mathrm{NDVI}_{\min }}\right]^{2}$

$\mathrm{NDVI}_{\text {max }}=0.5$

$\mathrm{NDVI}_{\min }=0.2$

The term in Eq. 1 includes the effect of the geometrical distribution of the natural surfaces and also the internal reflections. For plain surfaces, this term is negligible, but for heterogeneous and rough surfaces, as forest, this term can reach a value of $2 \%$. A good approximation for this term can be given by:

$\mathrm{d} \varepsilon=\left(1-\varepsilon_{\mathrm{S}}\right)\left(1-\mathrm{P}_{\mathrm{V}}\right) \mathrm{F} \varepsilon_{\mathrm{V}}$

where, $F$ is a shape factor whose mean value, assuming different geometrical distributions, is 0.55 (Sobrino et al., 1990).
Figure 5 showed the LST map generated from NDVI method. The obtained result from NDVI (Fig. 4) used to retrieve LST value. The same colour indicator was utilized to generate the LST maps, which is in Fig. 3 and 5. Both of these maps basically are different in terms of LST using both of these methods. Therefore, Eq. 4 was being used in order to evaluate the errors among both of these methods. There are many factors affect the value of LST. Hence, it will bring an error or uncertainty while using satellite image to retrieve LST. The retrieved LST values may be higher than the actual values because the effect of surface roughness is not taken into account when retrieving LST values (Weng, 2001). In addition, LST is also influenced by the land surface structure, water content and chemical composition (Snyder et al., 1998).

Table 1: Comparison between LST retrieved from ATCOR3_T and NDVI method for 23 January 2010

\begin{tabular}{|c|c|c|c|}
\hline $\mathrm{LST}_{\mathrm{ATCOR} 3 \_\mathrm{T}}$ & LST $_{\text {NDVI method }}$ & $\begin{array}{l}\mid \mathrm{LST}_{\text {ATCOR3_T }} \\
-\mathrm{LST}_{\text {NDVI method }} \mid\end{array}$ & Error $(\%)$ \\
\hline 27.25 & 30.93 & 3.68 & 11.90 \\
\hline 33.00 & 32.99 & 0.01 & 0.02 \\
\hline 35.00 & 35.02 & 0.02 & 0.05 \\
\hline 31.75 & 32.48 & 0.73 & 2.25 \\
\hline 31.75 & 31.97 & 0.22 & 0.07 \\
\hline 33.00 & 34.51 & 1.51 & 4.39 \\
\hline 28.25 & 30.93 & 2.68 & 8.67 \\
\hline 28.50 & 30.93 & 2.43 & 7.86 \\
\hline 29.75 & 31.97 & 2.22 & 6.93 \\
\hline 31.75 & 32.48 & 0.73 & 2.25 \\
\hline 33.00 & 33.50 & 0.50 & 1.50 \\
\hline 34.00 & 34.01 & 0.01 & 0.03 \\
\hline 36.25 & 35.02 & 1.23 & 3.52 \\
\hline 37.25 & 35.52 & 1.73 & 4.87 \\
\hline 38.25 & 35.52 & 2.73 & 7.69 \\
\hline 39.25 & 37.01 & 2.24 & 6.05 \\
\hline 35.00 & 34.01 & 0.99 & 2.91 \\
\hline 36.25 & 36.52 & 0.27 & 0.73 \\
\hline 37.25 & 35.52 & 1.73 & 4.87 \\
\hline 37.25 & 36.02 & 1.23 & 3.42 \\
\hline 29.75 & 32.48 & 2.73 & 8.41 \\
\hline 31.75 & 33.50 & 1.75 & 5.22 \\
\hline 27.50 & 30.93 & 3.43 & 11.09 \\
\hline 26.25 & 29.89 & 3.64 & 12.18 \\
\hline 28.50 & 31.97 & 3.47 & 10.85 \\
\hline 29.75 & 31.97 & 2.22 & 6.94 \\
\hline 36.25 & 34.51 & 1.74 & 5.04 \\
\hline 37.25 & 35.02 & 2.23 & 6.37 \\
\hline 36.25 & 35.52 & 0.73 & 2.06 \\
\hline 33.00 & 35.02 & 2.02 & 5.77 \\
\hline 37.25 & 36.02 & 1.23 & 3.41 \\
\hline 39.25 & 36.02 & 3.23 & 8.97 \\
\hline 31.75 & 32.99 & 1.24 & 3.76 \\
\hline 35.00 & 35.02 & 0.02 & 0.06 \\
\hline 34.00 & 33.50 & 0.50 & 1.49 \\
\hline 36.25 & 34.51 & 1.74 & 5.04 \\
\hline 34.00 & 35.52 & 1.52 & 4.28 \\
\hline 33.00 & 34.01 & 1.01 & 2.97 \\
\hline 27.25 & 30.93 & 3.68 & 11.90 \\
\hline 28.50 & 31.45 & 2.95 & 9.38 \\
\hline \multicolumn{3}{|c|}{ Average of the total error $(\%)$} & 5.13 \\
\hline
\end{tabular}


From Eq. 4, the average of all 40 points has been calculated by considering the value of LST from low to high. Table 1 shows the obtained result for all 40 points used for validated for every single satellite images. The average percentage of total error is $5.13 \%$.

This means that LST value generated from ATCOR3_T is suitable to generate LST value in tropical region using satellite image. From both of the generated map of LST, there are obvious that LST values are different using both different methods to retrieve LST. The range of LST for verification covered the LST value from low to high range in order to cover all the LST as much as possible. There are many factors bring to this effect, especially the noise created by sensor. However, the error is in the acceptable range and less than $10 \%$.

\section{CONCLUSION}

The study on the comparison of LST using different proposed methods showed that both of these methods successfully retrieve LST value in tropical region, especially in Penang Island. The verification of average of total error for LST value using ATCOR3_T with the NDVI method is $5.13 \%$. Thus, both of these methods can be used to retrieve LST for future study. In addition, the comparison of LST value from historical data can give significant view on the changing of LST value in the desired study area. Besides that, in order to improve the results obtained from LST, the temperature of every part in the vegetation-ground system must be taken into consideration (Cassels et al., 1992a; 1992b). Furthermore, the effects of different canopy structures may also affect surface temperature. Thus, for future study, all these factors should taking into consideration, in order to retrieve LST value in the same study area and may improve the obtained results.

\section{ACKNOWLEDGEMENT}

This project was carried out using the USM-RUPRGS grant, no. account: 1001/PFIZIK/831024. We would like to thank the technical staff who participated in this project. Thanks are also extended to USM for support and encouragement.

\section{REFERENCES}

Becker, F. and Z.L. Li, 1990. Towards a local split window method over land surfaces. Int. J. Remote Sens., $\quad 11$ : 369-393. DOI: $10.1080 / 01431169008955028$
Cassels, V., J.A. Sobrino and C. Coll, 1992a. A physical model for interpreting the land surface temperature obtained by remote sensors over incomplete canopies. Remote Sens. Environ., 39: 203-211. DOI:10.1016/0034-4257(92)90086-Y

Cassels, V., J.A. Sobrino and C. Coll, 1992b. On the use of satellite thermal data for determining evapotranspiration in partially vegetated areas. Int. J. Remote Sens., 13: 2669-2682. DOI: $10.1080 / 01431169208904071$

Chander, G., B.L. Markham and D.L. Helder, 2009a. Summary of current radiometric calibration coefficients for Landsat MSS, TM, ETM+ and EO1 ALI sensors. Remote Sens. Environ., 113: 893-903. DOI:10.1016/j.rse.2009.01.007

Chander, G., B.L. Markham and D.L. Helder, 2009b. Revised Landsat-5 thematic mapper radiometric calibration. IEEE Geosci. Remote Sens. Lett., 4: 490-494. DOI: 10.1109/LGRS.2007.898285

Dousset, B. and F. Gourmelon, 2003. Satellite multisensor data analysis of urban surface temperatures and land cover. ISPRS J. Photo Remote Sens., 58: 43-54. DOI: 10.1016/S0924-2716(03)00016-9

Jiang, G.M. and Z.L. Li, 2008. Split-window algorithm for land surface temperature estimation from MSGI-SEVIRI data. Int. J. Remote Sens., 29: 6067-6074. DOI: 10.1080/01431160802235860

NASA, 2009. Landsat 7, Science Data Users Handbook, Chapter 11-Data Products, http://landsathandbook.gsfc.nasa.gov/handbook/ha ndbook_htmls/chapter11/chapter11.html.

NASA, 2010. Landsat 7, National Aeronautics and Space Administration. http://landsat.gsfc.nasa.gov/about/landsat7.html.

Norman, J.M.M. Divakarla and N.S. Goel, 1995. Algorithms for extracting information from remote thermal-IR observations of the Earth's surface. Remote Sens. Environ., 51: 157-168. DOI:10.1016/0034-4257(94)00072-U

Peres, L.F. and C.C. Dacamara, 2004. Land surface temperature and emissivity estimation based on the two-temperature method: Sensitivity analysis using simulated MSG/SEVIRI data. Remote Sens. Environ., $\quad 91$ : $377-389$. DOI:10.1016/j.rse.2004.03.011

Qin, Z. and A. Karnieli, 1990. Progress in the remote sensing of land surface temperature and ground emissivity using NOAA-AVHRR data. Int. J. Remote Sens., 20: 2367-2393. DOI: $10.1080 / 014311699212074$

Richter, R., 1990. A fast atmospheric correction algorithm applied to Landsat TM images. Int. J. Remote Sens., 11: 159-166. DOI: $10.1080 / 01431169008955008$ 
Schmugge, T., A. French, J., C. Ritchie, A. Rango and H. Pelgrum, 2002. Temperature and emissivity separation from multispectral thermal infrared observations. Remote Sens. Environ., 79: 189-198. DOI: 10.1016/S0034-4257(01)00272-3

Snyder, W.C., Z. Wan, Y. Zhang, Y.Z. Feng, 1998. Classification-based emissivity for land surface temperature measurement from space. Int. J. Remote Sens., 19: 2753-2774. DOI: $10.1080 / 014311698214497$

Sobrino, J.A., J.C. Jimenez-Munoz and L. Paolini, 2004. Land surface temperature retrieval from Landsat TM 5. Remote Sens. Environ., 90: 434-440. DOI: 10.1016/j.rse.2004.02.003

Sobrino, J.A., J.C. Jimenez-Munoz, J. LabedNachbrand and F. Nerry, 2002. Surface emissivity retrieval from digital airborne imaging spectrometer data. J. Geophys. Res., 107: 4729. DOI: 10.1029/2002JD002197.

Sobrino, J.A., V. Caselles and F. Becker, 1990. Significance of the remotely sensed thermal infrared measurements obtained over a citrus orchard. ISPRS J. Photo. Remote Sens., 44: 343354. DOI: 10.1016/0924-2716(90)90077-O
Weng, Q., 2001. A remote sensing-GIS evaluation of urban expansion and its impact on surface temperature in the Zhujiang Delta, China. Int. J. Remote Sens., 22: 1999-2014. DOI: 10.1080/713860788

Weng, Q., D. Lu and J. Schubring, 2004. Estimation of land surface temperature-vegetation abundance relationship for urban heat island studies. Remote Sens. $\quad$ Environ., 89: 467-483. DOI:10.1016/j.rse.2003.11.005

Xiao, H. and Q. Weng, 2007. The impact of land use and land cover changes on land surface temperature in a Karst area of China. J. Environ. Manage., 85: 245-257. DOI:10.1016/j.jenvman.2006.07.016

Yang, J.S. and Y.Q. Wang, 2002. Estimation of land surface temperature using landsat-7 ETM+ thermal infrared and weather station data. Proceeding of Huangshan International Thermal Infrared Remote Sensing Workshop, July 14-17, 2002. Huangshan, Anhui, PR China, pp: 467-483. http://www.ltrs.uri.edu/research/LST_page/paper4. doc 